\title{
MicroRNA-34 Family, Mechanisms of Action in Cancer: A Review
}

\author{
Hamidreza Maroof, Ali Salajegheh, Robert Anthony Smith and Alfred King-Yin Lam*
}

Cancer Molecular Pathology, School of Medicine and Griffith Health Institute, Griffith University, Gold Coast, Queensland, Australia

\begin{abstract}
Altered expression of the microRNA-34 family has been determined to be involved in the pathogenesis of many cancers. In this review, the current knowledge of the cancer-related mechanisms in relation to the modulatory effects of microRNA-34 family were analysed. Expression analysis of the microRNA-34 family has suggested that its members play significant roles in many aspects of cancer biology including proliferation, invasion/metastasis, apoptosis/cell survival, cell cycle/cell growth, migration, senescence/aging, angiogenesis, epigenetic silencing and methylation by regulation of the expression of their target genes. Thus, microRNA-34 family members could act as prognostic markers and therapeutic targets in human cancers.
\end{abstract}

Keywords: Cancer, carcinoma, miR-34a, miR-34b, miR-34c, tumour suppressor gene, miRNA-34 family.

\section{BACKGROUND}

microRNAs were described in 1993 by Lee and colleagues [1]. They are defined as a class of non-coding RNAs, usually 21-25 nucleotides long, which play key roles in the regulation of gene expression. MicroRNAs function at the post-transcriptional level through interaction with the 3' untranslated region (3' UTR) of target mRNAs. Their main function is to down-regulate gene expression, which they do in a variety of ways, including translational repression, mRNA cleavage, and deadenylation. miRNAs alter the function of major cellular pathways such as cell proliferation and differentiation [1,2]. Due to their important roles in cellular processes, miRNAs have become a very interesting potential tool in cellular therapy for diseases like cancer [3-6].

The human miR-34 family consists of three family members, namely, miR-34a, miR-34b and miR-34c. The family is one of the 18 mammalian microRNAs that have homologues identified in gene profiling of worms and flies [7]. miR-34a is 22 nucleotides long and has $86 \%$ homology (19/22 nt) and 82\% homology (18/22 nt) with miR-34b and miR-34c, respectively. Mature miR-34b and miR-34c consist of 23 nucleotides and have $83 \%$ homology to one another (19/23 nt). All miR-34 family members share strong homology in a region located 2-9 base pairs towards the 5' terminus of the mature miRNA sequence. This sequence is around 8 nucleotides in length, and is called the "seed region", which serves to guide the selection of similar sets of target genes.

Despite the similarities between the miR-34 family members, there are also differences in the way they are organised. miR-34a is located on chromosome 1p36.22.

*Address correspondence to this author at the Head of Pathology, Griffith Medical School, Gold Coast Campus, Gold Coast QLD 4222, Australia; Tel: +61 7 56780718; Fax: +61 7 56780303; E-mail: a.lam@griffith.edu.au
The promoter of miR-34a has $\mathrm{CpG}$ island motifs (genomic regions that contain a high frequency of $\mathrm{CpG}$ sites, that is $\mathrm{C}$ paired with $G$ sites) and induced hyper-methylation of the $\mathrm{CpG}$ islands in its promoter may be a factor in the downregulation of miR-34 expression in malignancies. By contrast, miR-34b and miR-34c are encoded on a single polycistronic transcript (a single mRNA which can code for several genes) located at chromosome 11q23.1. The region containing the miR-34b/c gene also contains fragile sites, which have a high potential for mutation in cancers. These sites may present a dominant mode of altered regulation for these microRNAs in cancers $[8,9]$.

Studies have demonstrated the direct correlation of miR34 family deregulation with epigenetic and genetic mechanisms in cancers of lung, skin [10-13], pancreas, ovary $[11,14,15]$, breast , urinary bladder, kidney $[11,15]$, colon $[16]$, prostate [17], liver [18, 19], brain [20, 21], cervix [22, 23], oesophagus [24] and the lymphoid system [25-27]. Antioncogenic functions of miR-34 family have also been noted in cancers of pancreas [11], lung [10], brain [28, 29], liver $[18]$, skin $[30,31]$, prostate $[11]$, bone $[32,33]$ as well as in leukaemia and lymphoma $[27,34]$. In these cancers, miR-34 family members contribute to carcinogenesis through different mechanisms.

\section{THE ROLE OF miR-34 FAMILY IN CANCER CELL PROLIFERATION}

The expression of miR-34a in the rat's liver was found to be up-regulated in response to DNA damage and oxidative stress created by methapyrilene, 2-acetyl aminofluorene (2$\mathrm{AAF}$ ) and two non-damaging liver carcinogens with unknown modes of action, monuron and chlorendic acid. In the study, it was shown that miR-34a blocked induced cell proliferation in male fisher rats [35]. Using nicotinamide and etoposide as therapeutic agents, cell proliferation was inhibited in leukemic cells via activation of the p53-tumor suppressor pathway and modulation of its target genes including cyclin-dependent kinase inhibitor $1 A$ (p21), 
NADPH oxidase activator (NOXA), myeloid cell leukemia sequence 1(Mcl-1) and Bcl2-associated X protein (BAX), all of which occurred due to up-regulation of miR-34a function [36].

Pramanik et al., 2011, have reported that cell proliferation was inhibited in subcutaneous and orthotopic xenografts of pancreatic cancer in mouse models by miR-34a up-regulation. They used a miR-34a nanovector and systemic intravenous delivery method to inhibit pancreatic cancer. This study also reported that enhanced miR-34a induced down-regulation of silent mating type information regulation 2 homolog 1(SIRT1) and Cluster of Differentiation 44 (CD44) in mouse models [37].

Pogribny et al., found that exposure to tamoxifen (antagonist of estrogen receptor) in female fisher F344 rats was an effective hepato-carcinogen drug and that overexpression of miR-34a could induce the downregulation of cell proliferation by inhibition of Notch1 protein [38].

Overall, the animal studies differentiate the effective role of the miR-34 family in hindering and modifying cancer cell development through targeting proliferative gene pathways..

A different study demonstrated that up-regulation of miR-34a inhibits human pancreatic cancer stem cells and cancer cell lines by targeting the anti-apoptotic factor BCL-2 (B-cell lymphoma 2), as well as CDK6 (cyclin Dependent Kinase 6) and SIRT1 when used in combination with chemotherapeutic agents such as 5-Aza-2'-deoxycytidine (5-Aza-dC) and histone deacetylase inhibitor, Vorinostat [39].

Wang et al., found that the pre-transfection of lung cancer cell lines (A549 and SBC-5) with miR-34a inhibited cancer cell proliferation in a p53-independent manner by increasing sensitivity to the chemotherapy drug, cisplatin, in part by down-regulation of SIRT1 [40].

The importance of the miR-34 family in regulating cellular proliferation lies in the pathways targeted by the microRNA. Induced miR-34a up-regulation by adriamycin, a DNA damaging agent, has been found to down-regulate cell proliferation by inhibition of the E2 transcription factor (E2F) pathway in human colon cancer cell lines (HCT116 and RKO) [16].

In aggregate, the restoration of miR-34 family expression by chemotherapeutic agents will provide mechanistic insights and potential therapeutic applications for further studies on patients with cancer. More specifically, these are promising reagents to elevate a patient's response to existing chemotherapy drugs.

Kumar et al., reported that in head and neck squamous cell carcinoma, induced expression of miR-34a inhibited cancer cell proliferation by down-regulation of its target genes including transcription factors, E2F transcription factor 3 (E2F3) and survivin [41].

Induced expression of miR-34a by the CCAAT enhancer binding protein alpha $(\mathrm{C} / \mathrm{EBP} \alpha-\mathrm{p} 42)$ in patients with acute myeloid leukaemia and in granulopoiesis due to mutation in the CCAAT/Enhancer-binding protein, alpha (CEBPA) gene, inhibited the ability of myeloid cells to proliferate via restraining the expression of $\mathrm{E} 2 \mathrm{~F} 3$ and transcription factor E2F transcription factor 1 (E2F1) [42]. Taken together, these findings suggest that dysregulation of E2F transcription factors and modulation of its expression by the activity of miR-34 family members might represent a novel therapeutic potential in treatment of some cancers. Transient transfection of miR-34a is also able to inhibit cell proliferation by targeting the met proto-oncogene (hepatocyte growth factor receptor) (c-Met) in brain tumour cell lines (glioma and medulloblastoma) [43]. Similarly, in another study, downregulation of $c$-Met by miR-34b overexpression inhibited non-small cell lung carcinoma proliferation, which subsequently altered downstream phosphorylation of p53 and Mdm2 which in turn lead to apoptosis in human nonsmall cell lung carcinoma cell lines (A549 and SPC-A-1) [44].

A study from Kasinski's group confirmed that induced expression of miR-34a using a lentivirus expression system supressed cell proliferation in both a kraslsl-G12D/+; Trp53LSL-R172H/+ lung cancer mouse model and kraslslG12D/+; Trp53LSL-R172H/+ lung cancer cells in culture. The action was via targeting the B-cell CLL/Lymphoma 2 (Bcl2) and $c$-Met genes and to some extent by supressing v-myc avian myelocytomatosis viral oncogene homolog $(c-M y c)$ and cyclin-dependent kinase 4 (Cdk4) [45]. In addition, delta-like1 homolog (DLK1), Notch homolog 1 (Notch1), $c$-Met and enhancer of zeste homolog 2 (Ezh2) have been identified as being regulated by both miR-34b and miR-34c in response to DNA damage and mitogenic signals [46].

Further functional analysis by Corney et al., indicated that cooperation of both miR-34b and miR-34c in neoplastic cell lines (OSN1 and OSN2) suppressed cell proliferation and colony formation by mediating function of $\mathrm{p} 53$ protein [46].

In addition, suppression of the expression of miR-34a and $\mathrm{miR}-34 \mathrm{c}$ has been found to be induced by $\mathrm{p} 63$, a family member of $\mathrm{p} 53$. This $\mathrm{p} 63$ repression of miR-34a and miR-34c was found to control cancer cell proliferation via removing miR-34a targeting of the cell cycle regulators (cyclin-dependent kinase 4) CDK4 and cyclin D1 (CCND1) in primary keratinocytes and embryonic skin cells [47].

An in vivo and in vitro study on giloblastoma (brain tumour) revealed that miR-34a expression suppresses cell proliferation in the brain cancer through directly targeting the PDGF receptor (PDGFRA) [48]. Ramaiah et al., used anthranilamide-pyrazolo $[1,5-a]$ pyrimidine compound to activate the $p 53$ pathway by phosphorylation at serine residues 15,20 and 46, resulting in down-regulation of $v-m y c$ avian myelocytomatosis viral oncogene neuroblastoma derived homolog (MYCN) and mouse double minute 2 homolog $(\mathrm{mdm} 2)$ as oncogenic proteins. Subsequent to the effect of that compound, increased expression level of miR$34 \mathrm{a} / \mathrm{c}$ were also noticed which in turn lead to inhibition of cell proliferation via activation of apoptotic pathway in neuroblastoma cell lines (Neuro-2a, SK-N-SH and IMR-32) [49].

Furthermore, reconstitution of miR-34a expression in $p 53$ mutant human ovarian carcinoma restrained cell proliferation by down-regulation of CDK4 and in part inversely correlated with $c$-Met expression [50]. Collectively, $c-$ Met and the miR-34 
family work as key nodal points in the p53 network and will provide new therapeutic insight with emphasis on the connected roles of c-Met and miR-34. Furthermore, it indicates that $\mathrm{miR} 34-\mathrm{b} / \mathrm{c}$ and miR-34 a/c act in combination to play important roles in controlling carcinogenesis in diverse cell types, rather than individual miR-34 family members operating alone.

Intriguingly, it has been demonstrated that induction of miR-34c by bone morphogenetic protein 2 (BMP2) during osteoblast differentiation directly provokes the proliferative effect of Notchland Notch homolog 2 (Notch2) and jagged 1 (JAGl) at the post-transcriptional level in osteoblast cells and osteoblast progenitors in cell line. This mechanism has been seen to play a pivotal role in osteosarcoma pathogenesis [51].

Concepcion and colleagues showed a correlation between expression level of the miR-34 family and cell proliferation in mice with deletions in miR-34 family target genes. Slight elevation of cell proliferation has been observed in mice with reduced or absent miR-34 family expression. Interestingly, no increase in carcinogenesis, as initiated by c-Myc, was observed in these mice. These findings reported by Concepcion and colleagues implied that $\mathrm{p} 53$ function remains intact in miR-34 family deficient mice, perhaps through other feedback systems to maintain its expression [52].

$p 19$ (Arf) is a tumour suppressor gene product with a role independent of, but similar to p53 in cell development. In an in vitro study by Iqbal et al., it has been shown that induced expression of p19 (Arf) induces cell proliferation in eyespecific mouse embryo fibroblasts lacking p53, with indirect effects on platelet derived growth factor receptor beta (PDGFR $\beta$ ). Through introduction of induced miR-34a and inhibitors of miR-34a in the Arf-driven suppression of PDGFR $\beta$, this study has also identified a link that $A r f$, independent of p53 effect, correlated to miR-34a level and indicated that cell proliferation can be inhibited in p53independent ways [53].

Tanaka et al., reported that the down-regulation of miR34 family members induced cancer cell proliferation, resulting in an oncogenic phenotype in non-malignant human mesothelial cell lines, peritoneal mesothelial cells (LP-9) and primary-cultured mesothelial cells. This was accompanied by up-regulation of Bcl2, c-Met and phosphoc-Met proteins. Results demonstrated that miR-34 family down-regulation plays a pivotal role in the transformation of human non-malignant mesothelial cells to malignant mesothelial cells [54].

Circulating levels of miR-34 family in patients with colorectal and breast cancers have been studied by Nugent et al. They noted that, regardless of stage or grade of the cancers, the expression level of circulating miR-34a was considerably reduced. This suggested the potential application of miR-34a as a clinical biomarker [55].

Cell growth has been prevented by re-expression of miR34a in human p53-deficent pancreatic cancer cell lines (MiaPaCa2 and BxPC3) via down-regulation of Notch1 and Notch 2 and $B c l 2$, resulting in inhibition in the G1, and G2/M phases of the cell cycle [56]. In line with this report, research has indicated that the restored expression of miR-34a inhibits cell growth in 21 pancreatic ductal adenocarcinoma cell lines [57]. These findings suggest that restoration of the miR-34 family may provide a novel molecular therapy in human pancreatic cancer with loss of p53/miR-34 feedback loop.

Genistein, a natural compound and non-toxic activator of microRNAs, influences multiple biochemical functions in living cells and has anti-cancer activity. It has been shown that genistein causes up-regulation of miR-34a. Investigations on pancreatic cancer lines (AsPC-1 and $\mathrm{MiaPa}-2)$ showed that this up-regulation of miR-34a by genistein inhibits cell growth by down-regulation of Notch1 [58]. Overexpression of miR-34a has been associated with inhibition of cell growth and certain morphological features in prostatic cancer cell lines ( $\mathrm{VCaP}, 1 \mathrm{NCaP}, \mathrm{CWR} 22 \mathrm{rv} 1$ and C4-2B cells) through down-regulation of Notch1, androgen receptor and prostate-specific antigen (PSA) [59].

Use of anti-cancer agents (5-aza-Dc and BR-DIM) in the treatment of prostate cancer cell lines $(\mathrm{LNCaP}$ and C4-2B) and in tissue specimens with higher cancer grade (Gleason scores) was shown to lead to demethylation of the miR-34a promoter. Over-expression of miR-34a due to this demethylation inhibits cancer cell growth with downregulation of androgen receptor, prostate-specific antigen and Notch1 [60]. Therefore, direct targeting of Notch 1, androgen receptor and prostate specific antigen using reagents which have impact on re-expression of the miR-34 family instead of transfection of pre-miR-34 family would become an exquisite therapeutic strategy for patients with prostatic cancer.

In order to increase miR-34a expression in the breast cancer cell lines 184A1 and MCF-10A, Li et al., used T-VISA-miR-34a as a miR-43a expression vector in an orthotopic breast cancer mouse model. Robust expression of miR-34a was thus indicated to be involved with cell growth suppression through protein level down-regulation of SIRT1, $C D 44$ and $(E 2 F 3)$ as target genes of miR-34a. Intravenous injection of T-VISA- miR-34a markedly suppressed tumour growth without creation of systemic toxicity [61]. Thus a specific and safe targeted therapeutic approach for breast cancer could be achievable using T-VISA-miR-34a.

Accumulating evidence indicates that induced expression of miR-34b/c in small cell lung carcinoma cell lines (H1048 and SBC5) could inhibit cancer cell growth by downregulating the protein expression levels of the miR-34a target genes CDK6 and c-Met [62]. These results showed that miR$34 \mathrm{~b} / \mathrm{c}$ is frequently altered in small cell lung carcinoma and can be considered a potential therapeutic tool in war of small cell lung carcinoma.

In human pancreatic cancer cells and human pancreatic cancer stem cells, the up-regulation of miR-34a caused by therapeutic intervention of 5-Aza-Dc and SAHA agents, has been shown to inhibit cancer cell growth and cell cycle progression by down-regulation of SIRT1, CDK6 and B-cell CLL/lymphoma 2 (Bcl2) [39]. Induced expression of miR34a by delta-tocotrienol, a non-toxic miR-34a stimulator, was found to inhibit cancer cell growth in human non-small cell lung carcinoma cell lines (A549 and H1650) via downregulation of Notch1 and additional downstream targets including hairy and enhancer of split 1(Hes-1), BCL-2, 
CCND1 and survivin [63]. Thus, using activator reagents of the miR-34 family would offer a potential design point for novel anti-cancer drugs.

Down-regulation of miR-34a has been reported to be related with cell growth in giloblastoma cell lines (brain tumour cell lines - U373MG and SHG44) and tissue specimens through modulating directly the expression of Notch1 [28].

$\mathrm{Ji}$ and co-workers confirmed that the miR-34 family is a bona fide miRNA for cell arrest in the G1 phase and inhibition of cell growth in human gastric cancer cells (Kato III) cells via targeting $B c l 2$, high mobility group AT-hook 2 (HMGA2) and Notch1. Moreover, it is possible that restoration of p53 function in p53-deficient human gastric cancer cells may be induced by miR-34 family functions [64]. Therefore, creation of a novel molecular therapy is possible for p53-mutant gastric cancer through restoration of tumour suppressor miR-34.

Roy and colleagues reported that difluorinated curcumin (a synthetic analogue of curcumin) and 5-aza-2'-deoxycytidine (a methyltransferase inhibitor) were two reliable agents for promoter demethylation which can cause up-regulation of $\mathrm{miR}-34 \mathrm{a} / \mathrm{c}$. They demonstrated that up-regulation of miR$34 \mathrm{a} / \mathrm{c}$ in colon cancer cell lines (SW620, HCT116) inhibited cell growth in both chemo-sensitive and resistant colon cancer cells through targeting Notch1 [65].

In head and neck squamous cell carcinoma cell lines (UM-SCC-74A and UM-SCC-74B) and SCID mouse xenograft models, overexpression of miR-34a has been reported to be involved in inhibition of cancer cell growth by down-regulation E2F3 and survivin [41].

Bommer et al., observed that enhanced expression of miR-34 family members inhibited cancer cell growth by down-regulation of their target protein effector Bcl2 in nonsmall cell lung carcinomas [10].

$\mathrm{Li}$ and colleagues confirmed that expression levels of miR-34a inversely correlated to c-Met levels. In the study, re-expression of miR-34a supressed cell growth in human brain tumour cells (glioma and medulloblastoma). The action was due to by down-regulation of c-Met in medulloblastoma and in glioma cells by down-regulation of Notch $1 / 2$ and CDK6 protein expression. Also, in vivo investigation has shown the accelerated inhibition of glioma xenograft growth by transient expression of miR-34a [43].

Altogether, these finding showed that miR-34 family members are significant downstream effectors of $\mathrm{p} 53$ function and deregulated in multiple cancer subtypes. Upregulation of miR-34 family isoforms could potentially inhibit cancer cell proliferation and tumour growth by targeting multiple oncogenes. The concept could serve as an approach to treat cancer.

\section{THE ROLE OF miR-34 FAMILY IN CANCER INVASION AND METASTASES}

The deregulation of miR-34a has been proposed as a biomarker of metastasis in prostate cancer using xenografted lines from NOD (non-obese diabetic) and SCID (severe combined immunodeficiency) mice models. Studies have shown that down-regulation of miR-34a has direct correlation with metastatic capacity in these cancer xenograft lines [66]. In addition, miR-34a has been found to be significantly down-regulated in metastatic breast cancer tissues when compared to non-metastatic breast cancer, which are significantly associated with up-regulation of miR-34a. Thus, the expression level of miR-34a may be useful as a biomarker of metastasis [67].

miR-34 b/c have also been determined to play a crucial role in pathogenesis of small cell carcinoma of lung. Reduced expression of miR-34b and miR-34c due to promoter methylation has been revealed to correlate with invasive capacity of the small cell carcinoma of lung cell lines, H1048 and SBC5. Also, overexpression of miR-34b and miR-34c inhibited cancer cell invasion by targeting cMet and CDK6 in this cancer [62]. Furthermore, it has been shown that restoration of miR-34 family expression in a human pancreatic cancer cell lines, MiaPaCa2 and BxPC3, inhibited invasion by targeting BCL-2, Notch 1 and Notch2 [56]. These results delineated the fundamental role of miR34 family in tumour progression and its potential as a therapeutic target.

Li et al., in 2012, demonstrated that prolonged expression of miR-34a using T-VISA-miR34a as a highly specific expression vector of miR-34a can inhibit invasion in breast cancer cell lines (184A1, MCF-10A), by down-regulation of miR-34a target genes including SIRT1, CD44 and E2F3. This pattern of gene expression showed correlation in tissues, using a series of 22 human primary breast cancers [61]. Hence, using T-VISA-miR34a as a liposomal delivery system might be useful tool in regulation of a number of miR34a target genes and repressing of many different type of cancer.

Following treatment with the chromatin remodelling agents (5-Aza-Dc and SAHA) in human pancreatic cancer stem cells from primary cancers and cell lines, an increase in miR-34a expression was observed. This was associated with inhibition of invasion through targeting of BCL-2, CDK6 and SIRT1 [39]. Accordingly, this study implied a paramount role of miR-34a in pancreatic cancer progression by omitting the cancer stem cells characteristics. In support of these findings, lower expression level of miR-34b in (A549 and SPC-A-1) cell lines was associated with higher prevalence of lymph node metastasis in non-small cell lung carcinoma [44]. Thus, functional restoration of miR-34b may provide an effective novel therapy in non-small cell lung carcinoma signaling pathways.

c-Met has been known to be involved in migration and cell scattering in hepatocellular carcinoma cells. The upregulation of miR-34a in the HepG2 cell line inhibited the expression of c-Met via targeting the extracellular single-regulated kinase 1 and 2 (ERK1/2) pathway [18]. In agreement with this observation, c-Met protein expression and its 3' UTR reporter activity has been shown to be inhibited by miR-34a in brain tumour cell lines (medulloblastoma and gliomas). Furthermore, the upregulation of miR-34a also inhibits cancer cell invasion in glioma cells lines through targeting protein expression of Notch-1/2, confirmed by reductions in their 3' UTR reporter 
activity [43]. Overall, emphasis on dissection of miR-34a/cMet and Notch-1/2 interaction will provide a compelling rationale to develop of therapeutic application in cancers.

Induced expression of miR-34a was associated with inhibition of cell invasion, metastasis and pro-migratory cytoskeletal structure formation in human lung carcinoma and breast carcinoma cells through inhibition of the Rho GTPase activating protein 1 (Arhgapl) gene. The gene is responsible for production of the RHO GTPase protein [68].

Fos-related antigen-1 (Fra-1), a new target gene of miR$34 \mathrm{a}$, induces cell invasion in colon cancer cell lines (HCT116 and RKO). The overexpression of Fra-1 is influenced by matrix metallopeptidase 2 (MMP-2) and matrix metallopeptidase 9 (MMP-9) expression in invasive cells and can be inhibited by modulatory functions of p53 in a miR-34a-dependent manner. Emphasis on dissection of correlation between miR-34a and Fra-1 has unveiled that upregulation of miR-34a directly inhibited Fra-1 expression via targeting its 3' UTR [69]. These finding reflects the existence of miR-34a/ Arhgapl and miR-34a/ Fra-1 axes as an interaction pathway.

In cervical carcinoma and choriocarcinoma cell lines, miR-34a expression plays a role in reduction of invasion capacity by inhibition of urokinase plasminogen activator, which in turn, is mediated by Notch1 and Jagged1 [70].

Research has identified a correlation between CD44, an adhesion molecule associated with cancer stem and progenitor cells, in occurrence of cancer metastases in colon [71], head and neck [72], ovary [73], liver [74], stomach [75] and bladder [76] cancers. CD44 is also implicated as a predisposing factor for cancer stem cell invasion. Also, CD44 has been found to be a target of miR-34a. Overexpression of miR-34a inhibits cancer stem cell invasion and metastases by negative regulation of CD44 in a tumorigenic CD44+ prostate cancer cell line. Furthermore, evidence has shown the major role of miR-34a, as a modulator of $\mathrm{p} 53$, in negative regulation of CD44 via non-canonical p53 binding sites in the CD44 promoter [77]. Along the same lines, miR34 family members can influence the re-activation of $p 53$ as a tumour suppressor gene in p53 function deficient human pancreatic cancer cell lines [56]. In view of these reported actions of miR-34 family members in different cancer cells, in particular as a critical negative regulator of CD44+, miR-34 family function establishes a strong rationale for developing new therapy against cancer.

Beltran and co-workers demonstrated a further connection of miR-34a to invasion and metastasis, through the mammary serine protease inhibitor (maspin) in breast cancer in immunodeficiency mice and the breast cancer cell line MDA-MB-231. When expression of the maspin gene was induced through the use of an artificial transcription factor, it leads to inhibition of cancer metastasis. This occurred through up-regulation of miR-34a and other metastasis suppressor genes such as carnosine synthase 1 (CARNS1), dapper antagonist of beta-catenin homolog 3 (DACT3) and solute carrier family 8 (sodium/calcium exchanger), member 2 (SLC8A2) [78]. This result described for the first time that using the artificial transcription factor could lead to epigenetic reactivation of a dormant and normal-like gene and consequently reduction of cancer growth and metastases.

Chang and co-workers demonstrated that overexpression of miR-34a inhibited cancer cell invasion in hepatocellular carcinoma cells (HepG2) [79]. Siemens et al., showed that induced expression of miR-34a suppresses cancer cell invasion and metastasis by inhibition of Snail, a zinc finger transcriptional repressor, and transforming growth factor beta (TGF- $\beta$ ), which also play important roles in epithelialmesenchymal-transition (EMT) induction and enhancement of mesenchymal-epithelial-transition (MET) [80]. This finding demonstrated the principal role of Snail/miR-34 regulatory loop functions in reciprocal regulation of mesenchymal and epithelial status of cancer cells.

Induced down-regulation of miR-34 family members increased the invasion ability of cells by up-regulation of their target proteins c-Met and BCL-2 in human non-malignant peritoneal mesothelial cells (LP-9) and human primarycultured mesothelial cells [54]. This result showed that the transformation of human mesothelial cells to malignant mesothelial cells in the early cacinogenic process was accelerated with the functioal role of the miR-34 family.

Axl is a receptor that induces proliferation, migration and invasion in cancer. In non-small cell lung carcinoma, colorectal carcinoma and breast carcinoma, overexpression of miR-34a was shown to be inhibited distant metastasis by regulation of the Ax1 protein as an induced receptor of invasion and metastasis [81]. This finding showed that miR34a will have a positive association towards a long survival through Ax1 receptor regulation.

Kim et al., demonstrated that EMT-related invasion is associated with up-regulation of Snaill which increases due to a loss of p53 function and subsequently low expression of miR-34a. They showed that up-regulation of miR-34a inhibits cancer cell invasion by targeting Snaill and molecules that regulate Snaill function such as lymphoid enhancer-binding factor 1 (LEF1), axis inhibition protein 2 (Axin2) and $\beta$-catenin [82].

The p53-dependent expression level of miR-34a has been found to inhibit distant and nodal metastases by affecting EMT through a feedback loop, resulting in down-regulation of IL-6R(interleukin 6 receptor)/(signal transducer and activator of transcription 3) STAT3/miR-34a [83]. Moreover, p53-dependent overexpression of miR-34a that targets MET, as a key regulator of invasive growth, has been shown to inhibit cancer cell invasion and motility in primary mouse ovarian surface epithelium cell lines (OSN1 and OSN2) [84]. This finding highlights a pivotal role of Snail, IL-6R and STAT3 as downstream effectors of the p53/miR-34a axis in EMT aspect of carcinogenesis.

Expression of miR-34a suppresses cell invasion in the human renal carcinoma cell lines 769P and A498. In addition, miR-34a has been found to indirectly suppress ras homolog gene family, member A (RhoA) transcription through inhibition of c-Myc-Skp2(S-phase kinase-associated protein 2)-Miz1 (Myc-interacting zinc-finger protein 1) transcriptional complex assembly as well as the c-Myc-P- 
$\mathrm{TEFb}$ (positive transcription elongation factor) transcriptional elongation complex. Suppression of RhoA activity was associated with suppression of cancer invasion [85].

Taken together, these studies indicated novel aspects in the role of miR-34 family members in transcriptional regulatory function on invasion and metastasis through targeting of its involved specific genes and could therefore potentially be considered as a valuable therapeutic for metastatic types of cancer.

\section{THE ROLE OF miR-34 FAMILY IN CANCER APOPTOSIS AND CELL SURVIVAL}

In patients with chronic lymphocytic leukaemia, downregulation of miR-34a is implicated in apoptosis resistance, impaired DNA damage response and chemotherapy refractory disease through inhibition of $B A X$ and $p 21$. Irradiation stimulates miR-34a over expression that consequently regulates the expression of $p 53$ target genes including $B A X$ and $p 21$, but not $p 53$ up-regulated modulator of apoptosis (PUMA) [86].

Loss of expression of miR-34a (due to loss of $1 \mathrm{p} 36$ as the genomic region containing it) has frequently been reported in pancreatic cancer. Re-expression of miR-34a in nontransfected pancreatic adenocarcinoma cell lines (HPNE and HPDE) induced apoptosis via targeting p53-dependent mechanisms [14].

The restoration of miR-34 family members has been shown to stimulate apoptosis and chemo-sensitization to the anti-cancer drug, doxorubicin. The effect was related to the down-regulation of several target genes such as Bcl2, Notch1 and high mobility group AT-hook 2 (HMGA2) in p53defecient human gastric cancer cells (Kato III cells) [64].

Up-regulation of miR-34a in chronic lymphocytic leukaemia, in which the expression of SIRT1 commonly is increased, can induce apoptosis through targeting of p53dependent genes such as $p 21, N O X A$, myeloid cell leukemia sequence $1(M c l-1)$ and $B A X$. This can occur in cooperation with chemotherapeutic drugs (nicotinamide and etoposide) which have been identified as SIRT1 inhibitors [36].

In support of the significant role of miR-34a in cancer cell apoptosis, a further study showed that death receptor CD95 (APO- $1 /$ Fas), which is a p53 target gene, plays a critical role in stimulating cells to commit to apoptosis. Altered expression of CD95 promotes p53 activation, which results in regulation of miR-34a expression levels to respond to genotoxic stress and DNA damage [87].

Interestingly, Hi et al., reported that induced miR-34 family expression by irradiation and the anti-cancer drug, Adriamycin, increases apoptosis via targeting CDK6, E2F3, cyclin E2 (CCNE2) and BCL-2 in a p53-dependent manner in human osteosarcoma cell lines (U2OS and SAOS-2) [88].

Links were noted between miR-34a and apoptosis following treatment with 3,6-dihydroxyflavone (3,6-DHF), a chemo-preventive flavonoid anticancer drug. The treatment of the drug induced apoptosis in 1-methyl-1-nitrosouresa (MNU)-induced transplanted tumour growth in rats and $\mathrm{BALB} / \mathrm{C}$ nude mice using human breast cancer cell lines
(MDA-MB-453 and MDA-MB-231) [89]. This research showed that this apoptosis was accompanied by an increase in miR-34a, indicating a potential link between the two events. As another example, $J i$ et al., reported that treatment with delta-tocotrienol, a non-toxic miR-34a stimulator, has significant correlation with apoptosis induction and increases in p53 activity in human non-small cell carcinoma cell lines (A549 and H1650) through down-regulation of Notch1 and its concomitant downstream targets such as Hes-1, Bcl2, survivin and CCND1 [63].

Up-regulation of miR-34a due to stimulation by genistein, enhances cancer apoptosis through downregulation of Notch-1 in pancreatic cancer cell lines (AsPC1-1 and MiaPaCa-2) [58].

Wang et al., observed that the up-regulation of miR-34a in colon cancer cell line (HT29) is associated with enhanced cancer apoptosis by down-regulation of some of its targets that are involved in apoptosis process, such as Bcl2. This enhanced apoptosis is also associated with up-regulation of the DROSHA enzyme and increasing the binding between nuclear factor kappa beta (NFkB) and prostate apoptosis response protein 4 (par-4). The process resulted in inhibition of NFkB transport from cytoplasm to the nucleus. Prostate apoptosis response protein 4 (par-4) is also able to increase the sensitivity of colon cancer to the presence of anti-cancer drug, 5-fluorouracil (5-FU), via binding nuclear factor kappa beta $(\mathrm{NFkB})$ in the cytoplasm. This potential synergy with a known treatment compound is a potential avenue for the use of miR-34 family members in developing new combination therapies in cancers [90].

Induced expression of miR-34a in human glioma and medulloblastoma cells inhibits cell survival by downregulation of Notch1/2, CDK6 and c-Met expression [43]. A study in B-chronic lymphocytic leukaemia (B-CLL) showed that overexpression of miR-34a promotes apoptosis by upregulation of PUMA and $p 21$, which are targets of p53 [34]. This study also examined the correlation of miR-34a and single nucleotide polymorphism 309 (SNP309) in the promoter region of ubiquitin ligase murine double minute $\mathrm{z}$ protein (MDM2), a tight regulator of $\mathrm{p} 53$. It revealed that different genotypes of that single nucleotide polymorphism have significant differences in expression of miR-34a [34].

Ebnar et al., reported that induced expression of miR-34a and miR-34c inhibited the anti-apoptotic proteins FK506 binding protein 8 (Fkbp8) and vinculin (Vcl) in Hela cells [91]. In an exception to the usual state of miR-34 family expression in cancer cells, it has been found that the expression of miR-34a is severely elevated in a TCL1-mouse model of chronic lymphocytic leukemia as well as cell lines of human chronic lymphocytic leukemia. Induced expression of miR-34a induces apoptosis in HCT-116 cell lines with intact $\mathrm{p} 53$, and this response is removed when p53 itself was knocked down in these cells, providing further evidence of the link between p53 and miR-34a [92].

Yamakuchi et al., indicated the tumour suppressor function of miR-34a could regulate apoptosis in p53 wild type human colon cancer cells (HCT116) by SIRT1 protein inhibition which subsequently augmented the expression of PUMA and p21 and increased acetylation of p53 [93]. 
Kastl et al., found that resistance to Docetaxel, a chemotherapy drug that induces apoptosis, in breast cancer cell lines (MCF-7 and MDA-MB 231) was correlated with overexpression of miR-34a. It has been hypothesised that this connection occurs via targeting miR-34a's downstream target gens Bcl2 and CCND1 [94].

Down-regulation of Platelet-derived growth factor receptors $\alpha / \beta$ (PDGFR- $\alpha / \beta)$ by induced expression of $\mathrm{miR}-34 \mathrm{a} / \mathrm{c}$ has been found to induce apoptosis in lung cancer cell lines A549, H460, H1299 and H1703 by increasing sensitivity to TNF-related apoptosis inducing ligand (TRAIL)induced cell death [95].

Some efforts have been made to manipulate the miR-34 family system to modify the cancer cell behaviour. Thioacetamido modified nucleic acids that specially binds with an antisense oligonucleotide of miR-34a, have been shown to modulate cancer cell apoptosis in part through the oncogenes $M Y C N$ in a human embryonic kidney cell line (HEK293T) and mouse neuroblastoma cell line (Neuro 2a) [96].

Balca-Silva et al., observed that over expression of miR$34 \mathrm{a}$ inhibits cancer cell survival and increases radiosensitivity in the non-small cell lung carcinoma cell line A549 by down-regulation of $\mathrm{Bcl} 2$ [97].

miR-34a expression in the retinoblastoma cell lines Y79 promotes cancer cell apoptosis by down-regulation of target genes such as CCND1, calponin 2 (CNNE2), epithelial membrane protein 1( EMP1), CDK4, Mdm4 p53 binding protein homolog (MDMX), SIRT1 and E2F3 [98].

In pancreatic cancer stem cell self-renewal, the restoration of miR-34 family members by lentiviral miR-34MIF transfection induces apoptosis by down-regulation of the target genes Bcl2 and Notch1 [56]. miR-34a has also been reported to induce apoptosis in the pancreatic cancer cell line (MiaPaC-2) by down-regulation of SIRT1, aldehyde dehydrogenase and CD44. The study also demonstrated the potential therapeutic ability of this approach in pancreatic cancer xenograft mouse models, in both intra-pancreatic (orthotopic) and subcutaneously injected tumour forms [37].

$\mathrm{Hu}$ et al., have facilitated the penetration of miR-34a into pancreatic cells using a cationic nanovector that is comprised of bi-functional CC9 (CRGDKGPDC) peptides. Upregulation of miR-34a due to penetration with the nanovector induced apoptosis through decreased expression of Bcl2 and CCND1 in the human pancreatic carcinoma epithelial-like cell line (PANC-1 cell line) [99]. Re-expression of miR-34a in p53-null prostate cancer cell lines (PC3) has shown that the miR-34a apoptosis inducing effect in chemo-resistant cell lines occurs via down-regulation of SIRT1 mRNA and its protein [17]. Additionally, induced expression of miR-43a has found to be accompanied with sensitivity to Doxorubicin and induces apoptosis by down-regulation of Notch 1 in the human breast adenocarcinoma cell line (MCF-7) [100].

Members of the miR-34 family have been found to increase in expression due to captothecin, an inhibitor of DNA topoisomerase I, in p53-dependent and p53-independent manners by targeting NOXA, caspase-2, PUMA and BAX in Bows melanoma cell lines [101].
Sarveswaran et al., revealed that selenite, an anticancer nutritional supplement, could suppress LNCaP human prostate cancer cells through up-regulation of the proteinlevels of p53 targets gene including p21, BAX, PIG-3 (p53inducible gene 3 ) and DR5 (tumour necrosis factor receptor superfamily, member 10b) [102].

It is worth noting the physiologic role of the miR-34 family and its relation to apoptosis in non-cancer tissues. Niederer and co-workers indicated that the expression of mature sequence homo sapiens (has)-miR-34a-3p (miR-34a*) modulates apoptosis in rheumatoid arthritis synovial fibroblasts via directly targeting X-linked inhibitor of apoptosis (XIAP). They also showed that induced expression of miR-34a* correlates with Fas ligand (FASL) and tumor necrosis factor-related apoptosis-inducing ligand (TRAIL) rates that in turn play mediatory role in rheumatoid arthritis synovial fibroblasts (RASFs) apoptosis [103]. The expression of miR-34a in cardiomyocytes and induced apoptosis appear to be related with regulatory function of bone marrowderived mononuclear cells secreting insulin-like growth factor-1 [104]. Apoptosis in spermatogenesis is highly regulated and it has been shown that over expression of miR$34 \mathrm{c}$ in germ cells up-regulated germ cell specific genes such as spermatogenesis associated 17 (SPATA17), golgi-associated PDZ and coiled-coil motif containing (GOPC), kelch-like 10 (KLHL10) and sperm flagellar 2 (SPEF2) by targeting TGFB-induced factor homeobox 2 (TGIF2) and Notch2 in a p53-independent manner [105].

In order to assess molecular events occurring in carcinogenesis, the significant hallmark of cancer progression is identified to be "escape from apoptosis". Accumulating evidence demonstrated that deregulated miR-34 family plays a critical role in the process of p53-depended and p53independent apoptosis. In various types of cancers, downregulation of miR-34, as an anti-oncogene, has been observed to target anti-apoptotic genes in transcriptional and translational level. Furthermore, studies showed the miR-34 family play a pivotal role in altering sensitivity to chemotherapeutic treatment. Targeting of anti-apoptotic genes by miR-34 family members could serve a precious therapeutic approach in various types of cancer.

\section{THE ROLES OF miR-34 FAMILY IN CELL CYCLE PROGRESSION}

Induced expression of miR-34a in prostatic and pancreatic carcinoma cell lines triggered cell senescence and G1 cell cycle arrest in part via targeting CDK6. This finding also showed that induced expression of miR-34a is an effective tumour suppressor which is commonly inactivated through $\mathrm{CpG}$ methylation in promoter region [11].

In another study, Fujita and co-workers demonstrated that induced expression of miR-34a can dramatically decrease cell growth, enhance cell cycle arrest and eventually increase chemo-sensitivity to the anti-cancer drug camptothecin by targeting SIRT1 in prostatic cancer cell lines (PC3 and DU145) [17].

It is tempting to speculate that combinations of miRNAs, which act on the same pathways, could be more effective at suppression of cancer growth than each miRNA alone. 
Following this idea, Bandi and co-workers showed that miR$15 \mathrm{a} / 16$ in combination with miR-34a could cooperatively induce cell cycle arrest in the G1 and G0 phases. The combined treatment decreased the protein level of retinoblastoma and cyclin $\mathrm{E} 1$ in non-small cell lung carcinoma cell lines (A549, H1299, H358 and H2009). It also down-regulated the downstream targets of retinoblastoma such as CCND1, CDK4 and CDK6 [106].

A study from Li's group confirmed that expression levels of miR-34a inversely correlate to c-Met levels [43]. In that study, re-expression of miR-34a powerfully supressed cell growth and cell cycle progression in human brain tumour cells (glioma and medulloblastoma) by down-regulation of c-Met and in glioma cells by down-regulation of Notch $1 / 2$ and CDK6 protein expression. More in vivo investigation has shown the inhibition of glioma xenograft growth by transient expression of miR-34a [43].

Studies have implied that miR-34a could have a "cellfate determinant" function in early-stage division of colon cancer stem cells by regulating of its downstream effector Notch1 [107]. Transient transfection of miR-34a in hepatocellular carcinoma HepG2 cells inhibits cell cycle in G1 phase and accumulation of cells reduce in both $\mathrm{S}$ and G2 phase through down-regulation of its downstream target proteins including microtubule-actin crosslinking factor 1(MACF1), tropomyosin 4(TPM4) and cathepsin D. Along this theme, proteomic approaches have indicated that key target proteins of miR-34a in the formation of hepatocellular carcinoma included lamin A/C (LMNA), aldehyde dehydrogenase 2 family (ALDH2), LOC100129335 and microtubule-actin crosslinking factor 1 (MACF1) [79].

Re-introduction of miR-34a in neuroblastoma cell lines (SK-N-AS, Kelly, SK-N-BE and NGP) decreases cell cycle progression by down-regulation of E2F3 [29]. Gene inactivation of miR-34 family and p53 in prostatic epithelium of mice has been found to accompany an increase in the prostate stem and progenitor cell compartment by stimulating MET-dependent growth and self-renewal [108].

Zhao et al., reported that miR-34a induces inhibition of cancer cell proliferation in p53 -positive and in p-53 negative cells. Irrespective of p53 status, miR-34a inhibited cancer cell proliferation by up-regulation of CIP1/WAF1, a cell cycle-dependent kinase inhibitor, through downregulation of histone deacetylase 1 (HDAC1) which is a direct target of miR-34a. This finding provides an attractive therapeutic strategy for cancer patients [109].

Chen and co-workers indicated an inverse correlation between expression level of miR-34c and its target gene, cyclin E2 (CCNE2) in nasopharyngeal carcinoma tissue. Dysregulation of miR-34c could regulate G1-S cell cycle progression in nasopharyngeal carcinoma tissue via targeting CCNE2 level [110].

Overall, current evidence indicates that the miR-34 family directly target transcripts that encode proteins involved in cell cycle progression. Expression level of miR-34 family members may affect cell fate determination between apoptosis and cell cycle arrest. Furthermore, loss of cell cycle control is directly affected by alteration of miR-34 family expression level and can be involved in carcinogenesis.

\section{THE ROLE OF miR-34a FAMILY IN CELL SENESCENCE (AGING)}

In vitro and in vivo investigations by Tazawa et al., indicated that re-expression of miR-34a induces a senescence-like phenotype in two human colon cancer cell lines (HCT116 and RKO) by E2F signalling pathway downregulation and p53-pathway up-regulation [16]. He et al., reported that overexpression of $\mathrm{miR}-34 \mathrm{~b} / \mathrm{c}$ inhibits growth by down-regulation of c-Met expression, CDK4 and CCNE2 and continuing in this theme, substantially accelerated cellular senescence in a human foetal lung cell line (IMR90) and p53-deficient mouse embryonic fibroblasts by enhanced expression of senescence-associated beta-galactosidase (SA- $\beta-$ Gal) as a senescence marker [9].

The hippocampus is a centre of memory formation that can be influenced by aging, Alzheimer's disease and other neurodegenerative dementias. In vivo and in vitro investigation revealed that up-regulation of miR-34c has been implicated in disruptions of hippocampal function such as Alzheimer's disease and age-associated memory impairment in the aging hippocampus of APPPS1-21 mice models by down-regulation of hippocampal SIRT1 levels [111]. Interestingly, miR-34 family members, as part of the p53 pathway display a subtle role in senescence. Up-regulation of miR-34a, miR-34b and miR-34c in NHF-hTEFT cells (normal human fibroblast cells) by Nutlin-3 (an MDM2 inhibitor) induce senescence pathways in a p53 dependent manner [112].

Christoffersen et al., have shown a novel miR-34a expression pathway where miR-34a was regulated independently of p53 effects. In this pathway, miR-34a up-regulation transcriptionally induced by ETS family transcription factor and ELK1 (as a member of ETS oncogene family). Induced up-regulation of miR-34a enhanced cellular senescence in primary human TIG3 fibroblast cells through repression of the proto-oncogene Myc [113].

Yamkuch et al., reported that there is a positive feedback loop between miR-34a, p53 and SIRT1 in the senescence process. The SIRT1 gene has been considered to be involved in longevity limitation and cellular senescence. Expression of miR-34a has been induced by modulatory functions of p53. Induction of miR-34a down-regulates the expression of SIRT1, in turn elevating p53 activity [114].

miR-34 family up-regulation could modulate degeneration which is dependent on aging. This process was specifically observed in the organ of corti in $\mathrm{C} 57 \mathrm{BL} / 6 \mathrm{~J}$ and $\mathrm{CBA} / \mathrm{J}$ mice strains [115]. The expression level of miR-34 family members has been indicated to modulate age-related function in the brain by down-regulation of E74A, a transcriptional factor of the ETS domain, which plays a critical role in steroid hormone pathways. This can ablate damage caused by polyglutamine disease protein (ployQ) and affects aging and neuro-degeneration in flies, Drosophila [116]. In the study of Yang et al., it was demonstrated that the expression of miR-34a was enhanced during aging in rat tissue. 
Additionally, it was noted that in a nematode (Caenorhabditis elegans), a deletion mutation of miR-34a, extends lifespan (reducing senescence) and age-related physiological functions by inhibition of atg9 (an autophagyrelated protein) expression [117].

Inactivation of miR-34a by $\mathrm{CpG}$ methylation of its promoter is associated with senescence in many cancer types including prostate, breast, lung, colon, bladder, kidney and melanoma cell lines [11]. Ito et al., showed that over expression of miR-34a induces cellular senescence in primary human umbilical cord vein endothelial cells as well as heart and spleen cells of older mice, though suppression of SIRT1 protein [118]. Sun and co-workers indicated that overexpression of miR-34a induces cellular senescence by targeting G1 cell cycle arrest via suppressing CDK6 and CCND1 in non-small cell lung carcinoma cell line (A549) [119]. Overexpression of miR-34a induces cellular senescence via down-regulation $H D M X$ gene transcription in part by effects on p53 and Ras signalling pathways in breast cancer cell line (MCF-7), human colon carcinoma cell line (HCT-116) and human non-small cell lung carcinoma (H1299) and primary human diploid fibroblasts (IMR90) $[120,121]$.

To conclude, current studies demonstrated the biological ability of miR-34 family and its importance as a unique type of tumour suppressor to control cell proliferation and induction of senescence-like changes in cancer development process. These data could open a novel and promising therapeutic avenue to treat cancer and disease.

\section{THE ROLE OF miR-34 FAMILY IN CANCER CELL MIGRATION}

A wide array of migration mechanisms are utilized by cancer cells to allow them to disseminate to other locations. These mechanisms are to some degree independent on their invasive capacity. Dysregulation of microRNAs are noted to be involved in migration of cancer cells.

Induced expression of miR-34a by the using a T-VISAmiR-34a expression plasmid in breast cancer cell lines (184A1 and MCF-10A), resulted in persistent expression of miR-34a and suppressed cancer cell migration, demonstrating the therapeutic potential of miR-34a via targeting of $E 2 F 3$, CD44 and SIRT1 [61]. In support of the tumour suppressive role of miR-34b/c in small cell lung cancer cell lines (H1048 and SBC5), Tanaka et al., indicated that re-expression of miR-34b after 5-aza-2'-deoxycytidine treatment, significantly supressed cancer cell migration by down-regulation of two target genes $c$-Met and CDK6 [62]. In vivo investigation has shown that expression of miR-34a partially down-regulated Fra-1 as new target of miR-34a, in human colon cancer cell lines (HCT116 and RKO). Also, expression of miR-34a supressed cancer cell migration by down-regulation of MMP-2 and MMP-9, two enzymes that are implicated in cell migration and invasion, which can be rescued by Fra-1 overexpression. This implies that cancer cell migration and invasion are miR-34a-dependent mechanisms [69]. In addition, up-regulation of miR-34a has been observed to inhibit cancer cell migration and cancer cell scattering in hepatocellular carcinoma cell tissue and cell line (HepG2) through down- regulation of c-Met mRNA and protein and reducing phosphorylation of extracellular single-regulated kinases 1 and $2($ ERK1/2) [18].

Emerging evidence suggested that in the breast tumourinitiating cells (BT-ICs) of MCF-7 and SK-3rd cells (breast cancer cell lines enriched for BT-ICs), induced expression of miR-34c inhibit cancer cell migration via targeting Notch homolog 4 (Notch4) [122]. In addition, miR-34a overexpression restrained the ability of hepatocellular carcinoma cells (HepG2) to migrate [79]. In vivo and in vitro investigation, reported that re-expression of miR-34a restrained the migration ability of the human brain tumour (giloblastoma) cell line (U251). The process is a result of the down-regulation of cyclin-A1 (CCNA1), cyclin-B1(CCNB1), cyclin-D1(CCND1), cyclin-D3 (CCND3), cyclin-dependent kinase, epithelial growth factor receptor (EGFR) as well as Yin Yang-1(YY1), (an expression stimulator of EGFR) and up-regulation of p21 and p27 proteins, which are both cyclin kinase inhibitors [123].

Overexpression of miR-34a was shown to inhibit cell migration and energy production by down-regulation of 136 neural progenitor genes that are commonly involved with cell motility, electron transportation and oxidative phosphorylation based ATP synthesis in Wharton's jelly matrix of human umbilical cord cells and bone marrow mesenchymal stem cells [124]. The induced expression of miR-34a in colon cancer cell lines (SW480 and DLD-1) supresses cancer cell migration and increased chemosensitivity to anti-metabolite, 5-fluoracil, through downregulation of v-kit Hardy-Zuckerman 4 feline sarcoma viral oncogene homolog (c-Kit) and disruption of SCF/c-Kit axis, respectively [125].

miR-34a also affects migration in non-cancer tissue. In cartilage, chondroblast migration was reported to be negatively controlled by miR-34a expression levels and its relevant target EPH receptor A5 (epha5) during chondrogenesis, in particular in chick limb mesenchymal cells [126].

These results provide evidence that the miR-34 family is an inhibitor of cancer cell migration which was associated with modulation of various cancer signalling pathways and therefore replacement therapy with miR-34 family may offer an alternative for current therapeutic targeting of cancer.

\section{THE ROLE OF miR-34a IN ANGIOGENESIS PROCESSES}

Angiogenesis is necessary for survival of all mammalian cells, because their survival depends on obtaining sufficient oxygen and nutrients as well as disposing of waste. Association between angiogenesis and miRNAs was initially described in endothelial cells using miRNA microarrays tools. In general, changes to more than 200 miRNAs including both overexpression and attenuation have been determined to be involved in endothelial cell function and as well as in vascular functions. Given their role in metastasis and invasion, it is not surprising that the miR-34 family should be found to be involved in angiogenic processes.

E2F3a and E2F3b are an important family of transcriptional factors that play pivotal roles in cell 
proliferation and differentiation and cell cycle regulation [127-129]. In addition, E2F3a has a higher oncogenic potential activity as compared to other isoforms of the protein [130]. Also, expression of the protein survivin, an important oncogene protein, has a direct correlation with enhanced angiogenesis, reduced apoptosis, enhanced proliferation, resistance to chemotherapy, enhanced tumour recurrence and poor prognosis of patients with cancers [131136]. Kumar et al., demonstrated that overexpression of miR-34a inhibits tumour angiogenesis by down-regulation of the key angiogenic factor vascular endothelial growth factor (VEGF), (specifically VEGF A) and also demonstrated that overexpression of miR-34a suppresses angiogenic functions of endothelial cells by down-regulation of E2F3 (particularly the E2F3a isoform), survivin, SIRT1 and CDK4 in head \& neck squamous cell carcinoma cell lines (UM-SCC-74A and UM-SCC-74B) and in SCID mouse xenograft models [41].

Treatment failure in heart disease is most common in elderly populations and current therapeutic drugs have significant side effects. Existing evidence has showed the therapeutic potential of the miR-34 family, especially miR-34a, in pathological cardiac remodelling. Using a subcutaneously-delivered seed-targeting 8-mer LNA (locked nucleic acid)-modified antimiR (LNA-antimiR-34), Bernardo et al., silenced the miR-34 family in mice with myocardial infarction and transverse aortic constriction. As a result, mice showing pathological hypertrophy and disability due to chronic pressure overload showed improved heart function. It was also observed that angiogenesis increased in mice with myocardial infarction and transverse aortic constriction treated with the LAN-antimiR-34. This increased angiogenesis was associated with up-regulation of miR-34's direct targets such as VEGF-A, VEGF-B, vinculin, Notch1, sephaforin 4B and O-fucosyltransferas1. As a result, the improvement of heart function occurred [137].

In order to investigate the role of endothelial microRNAs in angiogenesis, Caporali et al., for the first time classified endothelial microRNAs into classes, placing the miR-34 family into the class of microRNAs whose expression depends on stimulation of anti-angiogenic factors [138, 139]. Independent studies have reported the correlation between angiogenesis and senescence in endothelial cells and endothelial progenitor cells (EPCs). Overexpression of miR34a has been seen to inhibit EPCs and thus mediate angiogenesis through induction of cellular senescence and down-regulation of SIRT1 and elevation of acetylated forkhead box protein $\mathrm{O} 1$ (FoxO1), a regulator transcription factor of stress response [139, 140]. SIRT1 in turn has a bidirectional relationship with endothelial nitric oxide synthase (eNOS) that plays a profound role in downregulation of angiogenesis in human umbilical vein endothelial cells, and in spleen and heart tissues in older mice [118]. Bone marrow-mononuclear cell therapy in patients with cardiovascular disease has showed that overexpression of miR-34a is associated with decreased bone marrow cell survival in acute myocardial infarction in aged mice. Accordingly, pre-treatment of bone marrowmononuclear cells with LNA-34a (as a miR-34a expression inhibitor) in patients with coronary artery disease can be considered a therapeutically advantageous approach [141].
Myc expression has been reported to correlate with miR17-92 related tumour angiogenesis and formation of B-cell lymphoma. It is also known that miR-34c regulates Myc expression as one of its main targets in response to DNA damage. Therefore, it is possible that miR-34c operates upstream of miR-17-92 and participates in deregulation of angiogenesis through Myc [142].

Recent studies showed that miR-34 family as microRNA with dual anti-tumour and anti-angiogenic profiles. The fine tuning regulatory role in angiogenesis network by miR-34 might also be a potential prognostic marker in different cancers. Therefore, the maintenance of miR-34 family cellular function is essential for an appropriate angiogenic response.

\section{THE ROLE OF PROMOTER METHYLATION IN miR-34 FAMILY ACTIVITY}

The expression of miR-34a is known to regulate the expression of androgen receptor and prostatic specific antigen. Both receptors are associated with poor outcomes in prostate cancer. Consequently, the loss of miR-34a due to hyper-methylation of its promoter has been identified in prostate cancer tissue specimens. Thus, the demethylation of the miR-34a promoter and restoration of its expression provides a potentially effective avenue for treatment of prostate cancer [143].

Lodygin et al., showed that aberrant DNA methylation of miR-34a promoter was associated with down-regulation of miR-34a in many cancers cell lines including prostate carcinoma, breast carcinoma, lung carcinoma, colon carcinoma, bladder carcinoma, renal carcinoma and melanoma. This was due to transcriptional silencing of miR$34 \mathrm{a}$ in these cancers. Indeed, loss of miR-34a expression due to promoter $\mathrm{CpG}$ methylation, has been identified in almost eighty percent of primary prostate carcinoma [11].

In stage I non-small cell lung carcinoma, aberrant hypermethylation of mature miR-34b and miR-34c promoters were associated with more cancer recurrence and poorer survival rates. Hence, miR-34b/c methylation or expression could thus be a potentially useful prognostic marker for nonsmall cell lung carcinoma [144].

Methylation of miR-34 family promoter regions preferentially occurs in colorectal cancers expressing wildtype p53 and inactivation of miR-34 family genes by hypermethylation may substitute for loss of p53 function in colorectal cancers [15]. Also, single hyper-methylation in the promoter region of miR-34c is associated with its downregulation in breast carcinoma cells which in turn stimulates self-renewal and induced epithelial-mesenchymal transition [122]. Nalls et al., indicated that re-expression of miR-34a inhibits epithelial-mesenchymal transition and self-renewal in pancreatic cancer stem cells by down-regulation of the Notch pathway, down-regulation of N-cadherin and upregulation of E-cadherin [39]. Furthermore, Wong et al., found that promoter hyper-methylation of miR-34b and miR-34c is found to occur in multiple myeloma cells. Re-expression of miR-34b but not miR-34c by using 5 -Aza2'-deoxycytidine inhibited myeloma proliferation and 


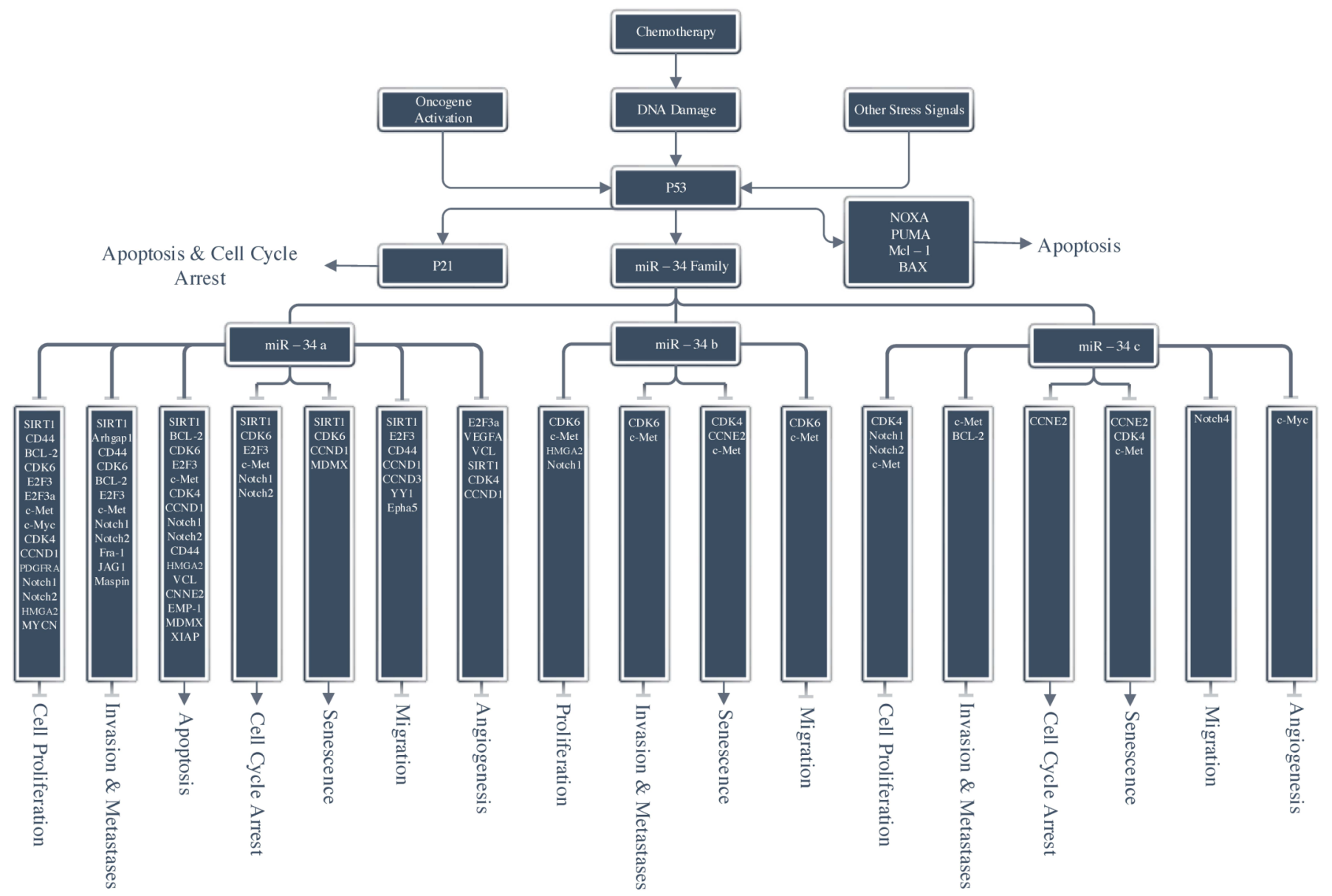

Fig. (1). The diverse roles of miR-34 family in the mechanims of cancer. The members of the miR-34 family act on different proceses in the body through different genes. The disrutption of these pathways will lead to cancer. The miR-34 family members are downstream factors in the 553 pathway.

increased apoptosis in bone marrow sample of myeloma patients [145]. In line with this report, Toyota et al., demonstrated the hyper-methylation of the miR-34b/c promoter $\mathrm{CpG}$ island and B-cell translocation gene 4 (BTG4) in the colon cancer cell line HCT116. This region was indicated to be a bidirectional promoter which regulates the expression level of both BTG4 and miR-34b/c. Therefore, there is a compelling rationale for the possibility that miR$34 \mathrm{~b} / \mathrm{c}$ and BTG4 play dual tumour suppressor roles in colorectal cancer [146]. Moreover, Siemens et al., identified the inverse correlation between miR-34a promoter hypermethylation and elevated expression level of its targets including c-Met, $\beta$-catenin in liver metastases of colon cancer. Furthermore, the development risk of distant metastases has been identifies in patients with primary colon carcinomas that were positive for miR-34a promoter hypermethylation in combination with c-Met and $\beta$-catenin expression levels [147].

Overall, hyper-methylation of promoter in miR-34 family is relatively common event which can be presumably substituted for $\mathrm{p} 53$ inactivation in broad range of cancers. Thus, restoration of silenced miR-34 family by epigenetic drugs may lead to reduced effectiveness of oncogenes and hopefully even therapies in diverse types of cancer.

\section{CONCLUSION}

The miR-34 family is a class of non-coding tumour suppressors, playing a major role in carcinogenesis. In this paper, the links between the roles of miR-34 family and their protein targets that facilitate a desirable environment for carcinogenesis when their normal expression is perturbed were reviewed. There is a very clear link between loss of miR-34 family expression and development/progression of many human cancers (Fig. 1). The miR-34 family also has potential to be used as additional or even surrogate markers for prognosis diagnosis of human cancers. Interestingly, there are many known compounds that can up-regulate miR34 family expression levels, which in turn could serve to improve cancer treatment and inhibit growth of cancer cells. Without a doubt, our current understanding of the miR-34 family's functional role and its targets is incomplete and deserves future investigation. This incomplete knowledge underscores the complexity of the miR-34 family's roles in cellular pathways.

Of the questions that remain, the relationship between elevated resistance to certain chemotherapeutic drugs and radiation with loss of expression of the miR-34 family is one greatly worth investigation. Thus far, there is not a clear mechanistic explanation of how this occurs. Meanwhile, no 
miR-34 family target gene has been identified that would explain this activity of the miR-34 family. Regardless of the answer to this question, restored expression of miR-34 family in cancers where it has been lost holds great therapeutic potential for treatment of cancer. Therefore, continued investigation on the detailed characterization of miR-34 family member functions and their target genes will be needed to clarify their role in carcinogenesis and assist in improving the design of therapeutic drug targeting regimes in human cancers.

\section{CONFLICT OF INTEREST}

The author(s) confirm that this article content has no conflict of interest.

\section{ACKNOWLEDGEMENTS}

The authors would like to acknowledge funding from Griffith University for the support of the work.

\section{REFERENCES}

[1] Lee RC, Feinbaum RL, Ambros V. The C. elegans heterochronic gene lin-4 encodes small RNAs with antisense complementarity to lin-14. Cell. 1993; 75: 843-54.

[2] Ruvkun G. Glimpses of a Tiny RNA World. Science. 2001; 294: 797-9.

[3] Gopalan V, Pillai S, Ebrahimi F, Salajegheh A, Lam TC, Le TK, Langsford N, Ho YH, Smith RA, Lam AK. Regulation of microRNA-1288 in colorectal cancer: Altered expression and its clinicopathological significance. Mol Carcinog. 2014; 53: E36E44.

[4] Ebrahimi F, Gopalan V, Smith RA, Lam AK. miR-126 in human cancers: Clinical roles and current perspectives. Exp Mol Pathol. 2014; 96: 98-107.

[5] Nelson JB, Nabulsi AA, Vogelzang NJ, Breul J, Zonnenberg BA, Daliani DD, Schulman CC, Carducci MA. Suppression of prostate cancer induced bone remodeling by the endothelin receptor a antagonist Atrasentan. J Urol. 2003; 169: 1143-9.

[6] Serpico D, Molino L, Di Cosimo S. microRNAs in breast cancer development and treatment. Cancer Treat Rev. 2014; 40: 595-604.

[7] Ruby JG, Jan C, Player C, Axtell MJ, Lee W, Nusbaum C, Ge H, Bartel D. Large-scale sequencing reveals 21U-RNAs and additional microRNAs and endogenous siRNAs in C. elegans. Cell. 2006; 127: 1193-207.

[8] Calin GA, Sevignani C, Dumitru CD, Hyslop T, Noch E, Yendamuri S, Shimizu M, Rattan S, Bullrich F, Negrini M, Croce $\mathrm{CM}$. Human microRNA genes are frequently located at fragile sites and genomic regions involved in cancers. Proc Natl Acad Sci U S A. 2004; 101: 2999-3004.

[9] He L, He X, Lim LP, de Stanchina E, Xuan Z, Liang Y, Xue W, Zender L, Magnus J, Ridzon D, Jackson AL, Linsley PS, Chen C, Lowe SW, Cleary MA, Hannon GJ. A microRNA component of the p53 tumour suppressor network. Nature. 2007; 447: 1130-4.

[10] Bommer GT, Gerin I, Feng Y, Kaczorowski AJ, Kuick R, Love $\mathrm{RE}$, et al. p53-mediated activation of miRNA34 candidate tumorsuppressor genes. Curr Biol. 2007; 17: 1298-307.

[11] Lodygin D, Tarasov V, Epanchintsev A, Berking C, Knyazeva T, Korner $\mathrm{H}$, et al. Inactivation of miR-34a by aberrant $\mathrm{CpG}$ methylation in multiple types of cancer. Cell Cycle. 2008; 7: 2591600 .

[12] Gallardo E, Navarro A, Vinolas N, Marrades RM, Diaz T, Gel B, et al. miR-34a as a prognostic marker of relapse in surgically resected non-small-cell lung cancer. Carcinogenesis. 2009; 30: 1903-9.

[13] Wiggins JF, Ruffino L, Kelnar K, Omotola M, Patrawala L, Brown $\mathrm{D}$, et al. Development of a lung cancer therapeutic based on the tumor suppressor microRNA-34. Cancer Res. 2010; 70: 5923-30.

[14] Chang TC, Wentzel EA, Kent OA, Ramachandran K, Mullendore $\mathrm{M}$, Lee $\mathrm{KH}$, et al. Transactivation of miR-34a by p53 broadly influences gene expression and promotes apoptosis. Mol Cell. 2007; 26: 745-52.
[15] Vogt M, Munding J, Gruner M, Liffers ST, Verdoodt B, Hauk J, et al. Frequent concomitant inactivation of miR-34a and miR-34b/c by $\mathrm{CpG}$ methylation in colorectal, pancreatic, mammary, ovarian, urothelial, and renal cell carcinomas and soft tissue sarcomas. Virchows Arch. 2011; 458: 313-22.

[16] Tazawa H, Tsuchiya N, Izumiya M, Nakagama H. Tumorsuppressive miR-34a induces senescence-like growth arrest through modulation of the E2F pathway in human colon cancer cells. Proc Natl Acad Sci U S A. 2007; 104: 15472-7.

[17] Fujita Y, Kojima K, Hamada N, Ohhashi R, Akao Y, Nozawa Y, et al. Effects of miR-34a on cell growth and chemoresistance in prostate cancer PC3 cells. Biochem Biophys Res Commun. 2008; 377: 114-9.

[18] Li N, Fu H, Tie Y, Hu Z, Kong W, Wu Y, et al. miR-34a inhibits migration and invasion by down-regulation of c-Met expression in human hepatocellular carcinoma cells. Cancer Lett. 2009; 275: 44-53.

[19] Tryndyak VP, Ross SA, Beland FA, Pogribny IP. Down-regulation of the microRNAs miR-34a, miR-127, and miR-200b in rat liver during hepatocarcinogenesis induced by a methyl-deficient diet. Mol Carcinog. 2009; 48: 479-87.

[20] Feinberg-Gorenshtein G, Avigad S, Jeison M, Halevy-Berco G, Mardoukh J, Luria D, et al. Reduced levels of miR-34a in neuroblastoma are not caused by mutations in the TP53 binding site. Genes Chromosomes Cancer. 2009; 48: 539-43.

[21] Cole KA, Attiyeh EF, Mosse YP, Laquaglia MJ, Diskin SJ, Brodeur GM, et al. A functional screen identifies miR-34a as a candidate neuroblastoma tumor suppressor gene. Mol Cancer Res. 2008; 6: 735-42.

[22] Wang X, Wang HK, McCoy JP, Banerjee NS, Rader JS, Broker TR, et al. Oncogenic HPV infection interrupts the expression of tumor-suppressive miR-34a through viral oncoprotein E6. Rna. 2009; 15: 637-47.

[23] Li B, Hu Y, Ye F, Li Y, Lv W, Xie X. Reduced miR-34a expression in normal cervical tissues and cervical lesions with high-risk human papillomavirus infection. Int J Gynecol Cancer. 2010; 20: 597-604.

[24] Chen X, Hu H, Guan X, Xiong G, Wang Y, Wang K, et al. CpG island methylation status of miRNAs in esophageal squamous cell carcinoma. Int J Cancer. 2012; 130: 1607-13.

[25] Mraz M, Malinova K, Kotaskova J, Pavlova S, Tichy B, Malcikova Stano Kozubik K, Smardova J, Brychtova Y, Doubek M, Trbusek M, Mayer J, Pospisilova S. miR-34a, miR-29c and miR-17-5p are downregulated in CLL patients with TP53 abnormalities. Leukemia. 2009; 23: 1159-63.

[26] Chim CS, Wong KY, Qi Y, Loong F, Lam WL, Wong LG, et al. Epigenetic inactivation of the miR-34a in hematological malignancies. Carcinogenesis. 2010; 31: 745-50.

[27] Craig VJ, Cogliatti SB, Imig J, Renner C, Neuenschwander S, Rehrauer $\mathrm{H}$, et al. Myc-mediated repression of microRNA-34a promotes high-grade transformation of B-cell lymphoma by dysregulation of FoxP1. Blood. 2011; 117: 6227-36.

[28] Li WB, Ma MW, Dong LJ, Wang F, Chen LX, Li XR. MicroRNA34a targets notch1 and inhibits cell proliferation in glioblastoma multiforme. Cancer Biol Ther. 2011; 12: 477-83.

[29] Welch C, Chen Y, Stallings RL. MicroRNA-34a functions as a potential tumor suppressor by inducing apoptosis in neuroblastoma cells. Oncogene. 2007; 26: 5017-22.

[30] Yan D, Zhou X, Chen X, Hu DN, Dong XD, Wang J, et al. MicroRNA-34a inhibits uveal melanoma cell proliferation and migration through downregulation of c-Met. Invest Ophthalmol Vis Sci. 2009; 50: 1559-65.

[31] Greenberg E, Hershkovitz L, Itzhaki O, Hajdu S, Nemlich Y, Ortenberg $\mathrm{R}$, et al. Regulation of cancer aggressive features in melanoma cells by microRNAs. PLoS One. 2011; 6: e18936.

[32] Tarasov V, Jung P, Verdoodt B, Lodygin D, Epanchintsev A, Menssen A, et al. Differential regulation of microRNAs by p53 revealed by massively parallel sequencing: miR-34a is a p53 target that induces apoptosis and G1-arrest. Cell Cycle. 2007; 6: 1586-93.

[33] Yan K, Gao J, Yang T, Ma Q, Qiu X, Fan Q, et al. MicroRNA-34a inhibits the proliferation and metastasis of osteosarcoma cells both in vitro and in vivo. PLoS One. 2012; 7: e33778.

[34] Asslaber D, Pinon JD, Seyfried I, Desch P, Stocher M, Tinhofer I, et al. microRNA-34a expression correlates with MDM2 SNP309 polymorphism and treatment-free survival in chronic lymphocytic leukemia. Blood. 2010; 115: 4191-7. 
[35] Koufaris C, Wright J, Currie RA, Gooderham NJ. Hepatic microRNA profiles offer predictive and mechanistic insights after exposure to genotoxic and epigenetic hepatocarcinogens. Toxicol Sci uaflito; $v 1,8$ aisitti 43 , Rossi D, Gottardi D, D'Arena G, Laurenti L,

et al. Nicotinamide blocks proliferation and induces apoptosis of chronic lymphocytic leukemia cells through activation of the p53/miR-34a/SIRT1 tumor suppressor network. Cancer Res. 2011; 71: 4473-83.

[37] Pramanik D, Campbell NR, Karikari C, Chivukula R, Kent OA, Mendell JT, et al. Restitution of tumor suppressor microRNAs using a systemic nanovector inhibits pancreatic cancer growth in mice. Mol Cancer Ther. 2011; 10: 1470-80.

[38] Pogribny IP, Tryndyak VP, Boyko A, Rodriguez-Juarez R, Beland FA, Kovalchuk O. Induction of microRNAome deregulation in rat liver by long-term tamoxifen exposure. Mutat Res. 2007; 619: 30-7.

[39] Nalls D, Tang SN, Rodova M, Srivastava RK, Shankar S. Targeting epigenetic regulation of miR-34a for treatment of pancreatic cancer by inhibition of pancreatic cancer stem cells. PLoS One. 2011; 6: e24099.

[40] Wang X, Dong K, Gao P, Long M, Lin F, Weng Y, et al. microRNA-34a sensitizes lung cancer cell lines to DDP treatment independent of p53 status. Cancer Biother Radiopharm. 2013; 28: 45-50.

[41] Kumar B, Yadav A, Lang J, Teknos TN, Kumar P. Dysregulation of microRNA-34a expression in head and neck squamous cell carcinoma promotes tumor growth and tumor angiogenesis. PLoS One. 2012; 7: e37601.

[42] Pulikkan JA, Peramangalam PS, Dengler V, Ho PA, Preudhomme $\mathrm{C}$, Meshinchi $\mathrm{S}$, et al. C/EBPalpha regulated microRNA-34a targets E2F3 during granulopoiesis and is down-regulated in AML with CEBPA mutations. Blood. 2010; 116: 5638-49.

[43] Li Y, Guessous F, Zhang Y, Dipierro C, Kefas B, Johnson E, et al. MicroRNA-34a inhibits glioblastoma growth by targeting multiple oncogenes. Cancer Res. 2009; 69: 7569-76.

[44] Wang LG, Ni Y, Su BH, Mu XR, Shen HC, Du JJ. MicroRNA-34b functions as a tumor suppressor and acts as a nodal point in the feedback loop with Met. Int J Oncol. 2013; 42: 957-62.

[45] Kasinski AL, Slack FJ. miRNA-34 prevents cancer initiation and progression in a therapeutically resistant K-ras and p53-induced mouse model of lung adenocarcinoma. Cancer Res. 2012; 72: 5576-87.

[46] Corney DC, Flesken-Nikitin A, Godwin AK, Wang W, Nikitin AY. MicroRNA-34b and MicroRNA-34c are targets of p53 and cooperate in control of cell proliferation and adhesion-independent growth. Cancer Res. 2007; 67: 8433-8.

[47] Antonini D, Russo MT, De Rosa L, Gorrese M, Del Vecchio L, Missero C. Transcriptional repression of miR-34 family contributes to p63-mediated cell cycle progression in epidermal cells. J Invest Dermatol. 2010; 130: 1249-57.

[48] Silber J, Jacobsen A, Ozawa T, Harinath G, Pedraza A, Sander C, et al. miR-34a repression in proneural malignant gliomas upregulates expression of its target PDGFRA and promotes tumorigenesis. PLoS One. 2012; 7: e33844.

[49] Ramaiah MJ, Pushpavalli SN, Lavanya A, Bhadra K, Haritha V, Patel $\mathrm{N}$, et al. Novel anthranilamide-pyrazolo[1,5-a]pyrimidine conjugates modulate the expression of p53-MYCN associated micro RNAs in neuroblastoma cells and cause cell cycle arrest and apoptosis. Bioorg Med Chem Lett. 2013; 23: 5699-706.

[50] Corney DC, Hwang CI, Matoso A, Vogt M, Flesken-Nikitin A, Godwin AK, et al. Frequent downregulation of miR-34 family in human ovarian cancers. Clin Cancer Res. 2010; 16: 1119-28.

[51] Bae Y, Yang T, Zeng HC, Campeau PM, Chen Y, Bertin T, et al. miRNA-34c regulates Notch signaling during bone development. Hum Mol Genet. 2012; 21: 2991-3000.

[52] Concepcion CP, Han YC, Mu P, Bonetti C, Yao E, D'Andrea A, et al. Intact p53-dependent responses in miR-34-deficient mice. PLoS Genet. 2012; 8: e1002797.

[53] Iqbal N, Mei J, Liu J, Skapek SX. miR-34a is essential for p19driven cell cycle arrest. Cell Cycle. 2014; 13.

[54] Tanaka N, Toyooka S, Soh J, Tsukuda K, Shien K, Furukawa M, et al. Downregulation of microRNA-34 induces cell proliferation and invasion of human mesothelial cells. Oncol Rep. 2013; 29: 216974.

[55] Nugent M, Miller N, Kerin MJ. Circulating miR-34a levels are reduced in colorectal cancer. $J$ Surg Oncol. 2012; 106: 947-52.
[56] Ji Q, Hao X, Zhang M, Tang W, Yang M, Li L, et al. MicroRNA miR-34 inhibits human pancreatic cancer tumor-initiating cells. PLoS One. 2009; 4: e6816.

[57] Kent OA, Mullendore M, Wentzel EA, Lopez-Romero P, Tan AC, Alvarez $\mathrm{H}$, et al. A resource for analysis of microRNA expression and function in pancreatic ductal adenocarcinoma cells. Cancer Biol Ther. 2009; 8: 2013-24.

[58] Xia J, Duan Q, Ahmad A, Bao B, Banerjee S, Shi Y, et al. Genistein inhibits cell growth and induces apoptosis through upregulation of miR-34a in pancreatic cancer cells. Curr Drug Targets. 2012; 13: 1750-6.

[59] Kashat M, Azzouz L, Sarkar SH, Kong D, Li Y, Sarkar FH. Inactivation of AR and Notch-1 signaling by miR-34a attenuates prostate cancer aggressiveness. Am J Transl Res. 2012; 4: 432-42.

[60] Kong D, Heath E, Chen W, Cher M, Powell I, Heilbrun L, et al. Epigenetic silencing of miR-34a in human prostate cancer cells and tumor tissue specimens can be reversed by BR-DIM treatment. Am J Transl Res. 2012; 4: 14-23.

[61] Li L, Xie X, Luo J, Liu M, Xi S, Guo J, et al. Targeted expression of miR-34a using the T-VISA system suppresses breast cancer cell growth and invasion. Mol Ther. 2012; 20: 2326-34.

[62] Tanaka N, Toyooka S, Soh J, Kubo T, Yamamoto H, Maki Y, et al. Frequent methylation and oncogenic role of microRNA-34b/c in small-cell lung cancer. Lung Cancer. 2012; 76: 32-8.

[63] Ji X, Wang Z, Geamanu A, Goja A, Sarkar FH, Gupta SV. Deltatocotrienol suppresses Notch-1 pathway by upregulating miR-34a in nonsmall cell lung cancer cells. Int J Cancer. 2012; 131: 266877.

[64] Ji Q, Hao X, Meng Y, Zhang M, Desano J, Fan D, et al. Restoration of tumor suppressor miR-34 inhibits human p53mutant gastric cancer tumorspheres. BMC Cancer. 2008; 8: 266.

[65] Roy S, Levi E, Majumdar AP, Sarkar FH. Expression of miR-34 is lost in colon cancer which can be re-expressed by a novel agent CDF. J Hematol Oncol. 2012; 5: 58.

[66] Watahiki A, Wang Y, Morris J, Dennis K, O'Dwyer HM, Gleave $\mathrm{M}$, et al. MicroRNAs associated with metastatic prostate cancer. PLoS One. 2011; 6: e24950.

[67] Javeri A, Ghaffarpour M, Taha MF, Houshmand M. Downregulation of miR-34a in breast tumors is not associated with either p53 mutations or promoter hypermethylation while it correlates with metastasis. Med Oncol. 2013; 30: 413.

[68] Ahn YH, Gibbons DL, Chakravarti D, Creighton CJ, Rizvi ZH, Adams HP, et al. ZEB1 drives prometastatic actin cytoskeletal remodeling by downregulating miR-34a expression. $J$ Clin Invest. 2012; 122: 3170-83.

[69] Wu J, Wu G, Lv L, Ren YF, Zhang XJ, Xue YF, et al. MicroRNA34a inhibits migration and invasion of colon cancer cells via targeting to Fra-1. Carcinogenesis. 2012; 33: 519-28.

[70] Pang RT, Leung CO, Ye TM, Liu W, Chiu PC, Lam KK, et al. MicroRNA-34a suppresses invasion through downregulation of Notch1 and Jagged1 in cervical carcinoma and choriocarcinoma cells. Carcinogenesis. 2010; 31: 1037-44.

[71] Dalerba P, Dylla SJ, Park IK, Liu R, Wang X, Cho RW, et al. Phenotypic characterization of human colorectal cancer stem cells. Proc Natl Acad Sci U S A. 2007; 104: 10158-63.

[72] Prince ME, Sivanandan R, Kaczorowski A, Wolf GT, Kaplan MJ, Dalerba $\mathrm{P}$, et al. Identification of a subpopulation of cells with cancer stem cell properties in head and neck squamous cell carcinoma. Proc Natl Acad Sci U S A. 2007; 104: 973-8.

[73] Zhang S, Balch C, Chan MW, Lai HC, Matei D, Schilder JM, et al. Identification and characterization of ovarian cancer-initiating cells from primary human tumors. Cancer Res. 2008; 68: 4311-20.

[74] Yang ZF, Ho DW, Ng MN, Lau CK, Yu WC, Ngai P, et al. Significance of CD90+ cancer stem cells in human liver cancer. Cancer Cell. 2008; 13: 153-66.

[75] Takaishi S, Okumura T, Tu S, Wang SS, Shibata W, Vigneshwaran $\mathrm{R}$, et al. Identification of gastric cancer stem cells using the cell surface marker CD44. Stem Cells. 2009; 27: 1006-20.

[76] Chan KS, Espinosa I, Chao M, Wong D, Ailles L, Diehn M, et al. Identification, molecular characterization, clinical prognosis, and therapeutic targeting of human bladder tumor-initiating cells. Proc Natl Acad Sci U S A. 2009; 106: 14016-21.

[77] Liu C, Kelnar K, Liu B, Chen X, Calhoun-Davis T, Li H, et al. Identification of miR-34a as a potent inhibitor of prostate cancer progenitor cells and metastasis by directly repressing CD44. Nature Medicine. 2011; 17: 211. 
[78] Beltran AS, Russo A, Lara H, Fan C, Lizardi PM, Blancafort P. Suppression of breast tumor growth and metastasis by an engineered transcription factor. PLoS One. 2011; 6: e24595.

[79] Cheng J, Zhou L, Xie QF, Xie HY, Wei XY, Gao F, et al. The impact of miR-34a on protein output in hepatocellular carcinoma HepG2 cells. Proteomics. 2010; 10: 1557-72.

[80] Siemens H, Jackstadt R, Hunten S, Kaller M, Menssen A, Gotz U, et al. miR-34 and SNAIL form a double-negative feedback loop to regulate epithelial-mesenchymal transitions. Cell Cycle. 2011; 10: 4256-71.

[81] Mudduluru G, Ceppi P, Kumarswamy R, Scagliotti GV, Papotti M, Allgayer H. Regulation of Axl receptor tyrosine kinase expression by miR-34a and miR-199a/b in solid cancer. Oncogene. 2011;30: 2888-99.

[82] Kim NH, Kim HS, Li XY, Lee I, Choi HS, Kang SE, et al. A p53/miRNA-34 axis regulates Snaill-dependent cancer cell epithelial-mesenchymal transition. J Cell Biol. 2011; 195: 417-33.

[83] Rokavec M, Oner MG, Li H, Jackstadt R, Jiang L, Lodygin D, et al. IL-6R/STAT3/miR-34a feedback loop promotes EMT-mediated colorectal cancer invasion and metastasis. J Clin Invest. 2014; 124 : 1853-67.

[84] Hwang CI, Matoso A, Corney DC, Flesken-Nikitin A, Korner S, Wang $\mathrm{W}$, et al. Wild-type p53 controls cell motility and invasion by dual regulation of MET expression. Proc Natl Acad Sci U S A. 2011; 108: 14240-5.

[85] Yamamura S, Saini S, Majid S, Hirata H, Ueno K, Chang I, et al. MicroRNA-34a suppresses malignant transformation by targeting c-Myc transcriptional complexes in human renal cell carcinoma. Carcinogenesis. 2012; 33: 294-300.

[86] Zenz T, Mohr J, Eldering E, Kater AP, Buhler A, Kienle D, et al. miR-34a as part of the resistance network in chronic lymphocytic leukemia. Blood. 2009; 113: 3801-8.

[87] Hau A, Ceppi P, Peter ME. CD95 is part of a let-7/p53/miR-34 regulatory network. PLoS One. 2012; 7: e49636.

[88] He C, Xiong J, Xu X, Lu W, Liu L, Xiao D, et al. Functional elucidation of MiR-34 in osteosarcoma cells and primary tumor samples. Biochem Biophys Res Commun. 2009; 388: 35-40.

[89] Hui C, Yujie F, Lijia Y, Long Y, Hongxia X, Yong Z, et al. MicroRNA-34a and microRNA-21 play roles in the chemopreventive effects of 3,6-dihydroxyflavone on 1-methyl-1-nitrosourea-induced breast carcinogenesis. Breast Cancer Res. 2012; 14: R80.

[90] Wang BD, Kline CL, Pastor DM, Olson TL, Frank B, Luu T, et al. Prostate apoptosis response protein 4 sensitizes human colon cancer cells to chemotherapeutic 5-FU through mediation of an NF kappaB and microRNA network. Mol Cancer. 2010; 9: 98.

[91] Ebner OA, Selbach M. Quantitative Proteomic Analysis of Gene Regulation by miR-34a and miR-34c. PLoS One. 2014; 9: e92166.

[92] Merkel O, Asslaber D, Pinon JD, Egle A, Greil R. Interdependent regulation of p53 and miR-34a in chronic lymphocytic leukemia. Cell Cycle. 2010; 9: 2764-8.

[93] Yamakuchi M, Ferlito M, Lowenstein CJ. miR-34a repression of SIRT1 regulates apoptosis. Proc Natl Acad Sci U S A. 2008; 105: 13421-6.

[94] Kastl L, Brown I, Schofield AC. miRNA-34a is associated with docetaxel resistance in human breast cancer cells. Breast Cancer Res Treat. 2012; 131: 445-54.

[95] Garofalo M, Jeon YJ, Nuovo GJ, Middleton J, Secchiero P, Joshi P, et al. MiR-34a/c-Dependent PDGFR-alpha/beta Downregulation Inhibits Tumorigenesis and Enhances TRAIL-Induced Apoptosis in Lung Cancer. PLoS One. 2013; 8: e67581.

[96] Soni K, Gupta S, Gokhale SS, Dey R, Gunjal AD, Kumar VA, et al. Detection and knockdown of microRNA-34a using thioacetamido nucleic acid. Nucleic Acid Ther. 2013; 23: 195-202.

[97] Balca-Silva J, Sousa Neves S, Goncalves AC, Abrantes AM, CasaltaLopes J, Botelho MF, et al. Effect of miR-34b overexpression on the radiosensitivity of non-small cell lung cancer cell lines. Anticancer Res. 2012; 32: 1603-9.

[98] Dalgard CL, Gonzalez M, deNiro JE, O'Brien JM. Differential microRNA-34a expression and tumor suppressor function in retinoblastoma cells. Invest Ophthalmol Vis Sci. 2009; 50: 4542-51.

[99] Hu QL, Jiang QY, Jin X, Shen J, Wang K, Li YB, et al. Cationic microRNA-delivering nanovectors with bifunctional peptides for efficient treatment of PANC-1 xenograft model. Biomaterials. 2013; 34: 2265-76.

[100] Kovalchuk O, Filkowski J, Meservy J, Inytskyy Y, Tryndyak VP, Chekhun VF, et al. Involvement of microRNA-451 in resistance of the MCF-7 breast cancer cells to chemotherapeutic drug doxorubicin. Mol Cancer Ther. 2008; 7: 2152-9.

[101] Rudolf E, Rudolf K, Cervinka M. Camptothecin induces p53dependent and -independent apoptogenic signaling in melanoma cells. Apoptosis. 2011; 16: 1165-76.

[102] Sarveswaran S, Liroff J, Zhou Z, Nikitin AY, Ghosh J. Selenite triggers rapid transcriptional activation of $\mathrm{p} 53$, and $\mathrm{p} 53$-mediated apoptosis in prostate cancer cells: Implication for the treatment of early-stage prostate cancer. Int J Oncol. 2010; 36: 1419-28.

[103] Niederer F, Trenkmann M, Ospelt C, Karouzakis E, Neidhart M, Stanczyk J, et al. Down-regulation of microRNA-34a* in rheumatoid arthritis synovial fibroblasts promotes apoptosis resistance. Arthritis Rheum. 2012; 64: 1771-9.

[104] Iekushi K, Seeger F, Assmus B, Zeiher AM, Dimmeler S. Regulation of cardiac microRNAs by bone marrow mononuclear cell therapy in myocardial infarction. Circulation. 2012; 125: 1765$73, \mathrm{~s} 1-7$.

[105] Bouhallier F, Allioli N, Lavial F, Chalmel F, Perrard MH, Durand $\mathrm{P}$, et al. Role of miR-34c microRNA in the late steps of spermatogenesis. Rna. 2010; 16: 720-31.

[106] Bandi N, Vassella E. miR-34a and miR-15a/16 are co-regulated in non-small cell lung cancer and control cell cycle progression in a synergistic and Rb-dependent manner. Mol Cancer. 2011; 10: 55.

[107] Bu P, Chen KY, Chen JH, Wang L, Walters J, Shin YJ, et al. A microRNA miR-34a-regulated bimodal switch targets Notch in colon cancer stem cells. Cell Stem Cell. 2013; 12: 602-15.

[108] Cheng CY, Hwang CI, Corney DC, Flesken-Nikitin A, Jiang L, Oner GM, et al. miR-34 Cooperates with p53 in Suppression of Prostate Cancer by Joint Regulation of Stem Cell Compartment. Cell Rep. 2014; 6: 1000-7.

[109] Zhao J, Lammers P, Torrance CJ, Bader AG. TP53-independent function of miR-34a via $\mathrm{HDAC1}$ and $\mathrm{p} 21$ (CIP1/WAF1.). Mol Ther. 2013; $21: 1678-86$

[110] Chen HC, Chen GH, Chen YH, Liao WL, Liu CY, Chang KP, et al. MicroRNA deregulation and pathway alterations in nasopharyngeal carcinoma. Br J Cancer. 2009; 100: 1002-11.

[111] Zovoilis A, Agbemenyah HY, Agis-Balboa RC, Stilling RM, Edbauer D, Rao P, et al. microRNA-34c is a novel target to treat dementias. Embo j. 2011; 30: 4299-308.

[112] Kumamoto K, Spillare EA, Fujita K, Horikawa I, Yamashita T, Appella E, et al. Nutlin-3a activates p53 to both down-regulate inhibitor of growth 2 and up-regulate mir-34a, mir-34b, and mir34c expression, and induce senescence. Cancer Res. 2008; 68: 3193-203.

[113] Christoffersen NR, Shalgi R, Frankel LB, Leucci E, Lees M, Klausen $\mathrm{M}$, et al. $\mathrm{p} 53$-independent upregulation of miR-34a during oncogene-induced senescence represses MYC. Cell Death Differ. 2010; 17: 236-45.

[114] Yamakuchi M, Lowenstein CJ. MiR-34, SIRT1 and p53: the feedback loop. Cell Cycle. 2009; 8: 712-5.

[115] Zhang Q, Liu H, McGee J, Walsh EJ, Soukup GA, He DZ. Identifying microRNAs involved in degeneration of the organ of corti during age-related hearing loss. PLoS One. 2013; 8: e62786.

[116] Liu N, Landreh M, Cao K, Abe M, Hendriks GJ, Kennerdell JR, et al. The microRNA miR-34 modulates ageing and neurodegeneration in Drosophila. Nature. 2012; 482: 519-23.

[117] Yang J, Chen D, He Y, Melendez A, Feng Z, Hong Q, et al. MiR34 modulates Caenorhabditis elegans lifespan via repressing the autophagy gene atg9. Age (Dordr). 2013; 35: 11-22.

[118] Ito T, Yagi S, Yamakuchi M. MicroRNA-34a regulation of endothelial senescence. Biochem Biophys Res Commun. 2010; 398: 735-40.

[119] Sun F, Fu H, Liu Q, Tie Y, Zhu J, Xing R, et al. Downregulation of CCND1 and CDK6 by miR-34a induces cell cycle arrest. FEBS Lett. 2008; 582: 1564-8.

[120] Markey M, Berberich SJ. Full-length hdmX transcripts decrease following genotoxic stress. Oncogene. 2008; 27: 6657-66.

[121] Miller KR, Kelley K, Tuttle R, Berberich SJ. HdmX overexpression inhibits oncogene induced cellular senescence. Cell Cycle. 2010; 9: 3376-82.

[122] Yu F, Jiao Y, Zhu Y, Wang Y, Zhu J, Cui X, et al. MicroRNA 34c gene down-regulation via DNA methylation promotes self-renewal and epithelial-mesenchymal transition in breast tumor-initiating cells. J Biol Chem. 2012; 287: 465-73.

[123] Yin D, Ogawa S, Kawamata N, Leiter A, Ham M, Li D, et al. miR34a functions as a tumor suppressor modulating EGFR in glioblastoma multiforme. Oncogene. 2013; 32: 1155-63. 
[124] Chang SJ, Weng SL, Hsieh JY, Wang TY, Chang MD, Wang HW. MicroRNA-34a modulates genes involved in cellular motility and oxidative phosphorylation in neural precursors derived from human umbilical cord mesenchymal stem cells. BMC Med Genomics. 2011; 4: 65 .

[125] Siemens H, Jackstadt R, Kaller M, Hermeking H. Repression of cKit by p 53 is mediated by miR-34 and is associated with reduced chemoresistance, migration and stemness. Oncotarget. 2013; 4: 1399-415.

[126] Kim D, Song J, Kim S, Chun CH, Jin EJ. MicroRNA-34a regulates migration of chondroblast and IL-1beta-induced degeneration of chondrocytes by targeting EphA5. Biochem Biophys Res Commun. 2011; 415: 551-7.

[127] Chong JL, Tsai SY, Sharma N, Opavsky R, Price R, Wu L, et al. E2f3a and E2f3b contribute to the control of cell proliferation and mouse development. Mol Cell Biol. 2009; 29: 414-24.

[128] Asp P, Acosta-Alvear D, Tsikitis M, van Oevelen C, Dynlacht BD. E2f3b plays an essential role in myogenic differentiation through isoform-specific gene regulation. Genes Dev. 2009; 23: 37-53.

[129] Danielian P, Friesenhahn L, Faust A, West J, Caron A, Bronson R, et al. E2f3a and E2f3b make overlapping but different contributions to total E2f3 activity. Oncogene. 2008; 27: 6561-70.

[130] Chen C, Wells AD. Comparative analysis of E2F family member oncogenic activity. PLoS One. 2007; 2: e912.

[131] Kawasaki H, Toyoda M, Shinohara H, Okuda J, Watanabe I, Yamamoto $\mathrm{T}$, et al. Expression of survivin correlates with apoptosis, proliferation, and angiogenesis during human colorectal tumorigenesis. Cancer. 2001; 91: 2026-32.

[132] Lam AK, Saleh S, Smith RA, Ho YH. Quantitative analysis of survivin in colorectal adenocarcinoma: increased expression and correlation with telomerase activity. Hum Pathol. 2008; 39: 122933.

[133] Su L, Wang Y, Xiao M, Lin Y, Yu L. Up-regulation of survivin in oral squamous cell carcinoma correlates with poor prognosis and chemoresistance. Oral Surg Oral Med Oral Pathol Oral Radiol Endod. 2010; 110: 484-91.

[134] Tanaka K, Iwamoto S, Gon G, Nohara T, Iwamoto M, Tanigawa N. Expression of survivin and its relationship to loss of apoptosis in breast carcinomas. Clin Cancer Res. 2000; 6: 127-34.

[135] Tran J, Master Z, Yu JL, Rak J, Dumont DJ, Kerbel RS. A role for survivin in chemoresistance of endothelial cells mediated by VEGF. Proc Natl Acad Sci U S A. 2002; 99: 4349-54.
[136] Swana HS, Grossman D, Anthony JN, Weiss RM, Altieri DC. Tumor content of the antiapoptosis molecule survivin and recurrence of bladder cancer. N Engl J Med. 1999; 341: 452-3.

[137] Bernardo BC, Gao XM, Winbanks CE, Boey EJ, Tham YK, Kiriazis $\mathrm{H}$, et al. Therapeutic inhibition of the miR-34 family attenuates pathological cardiac remodeling and improves heart function. Proc Natl Acad Sci U S A. 2012; 109: 17615-20.

[138] Caporali A, Emanueli C. MicroRNA regulation in angiogenesis. Vascul Pharmacol. 2011; 55: 79-86.

[139] Zhao T, Li J, Chen AF. MicroRNA-34a induces endothelial progenitor cell senescence and impedes its angiogenesis via suppressing silent information regulator 1. Am J Physiol Endocrinol Metab. 2010; 299: E110-6.

[140] Menghini R, Casagrande V, Cardellini M, Martelli E, Terrinoni A, Amati F, et al. MicroRNA 217 modulates endothelial cell senescence via silent information regulator 1. Circulation. 2009; 120: 1524-32.

[141] Xu Q, Seeger FH, Castillo J, Iekushi K, Boon RA, Farcas R, et al. Micro-RNA-34a contributes to the impaired function of bone marrow-derived mononuclear cells from patients with cardiovascular disease. J Am Coll Cardiol. 2012; 59: 2107-17.

[142] Cannell IG, Bushell M. Regulation of Myc by miR-34c: A mechanism to prevent genomic instability? Cell Cycle. 2010; 9: 2726-30.

[143] Kong D, Heath E, Chen W, Cher M, Powell I, Heilbrun L, et al. Erratum: Epigenetic silencing of miR-34a in human prostate cancer cells and tumor tissue specimens can be reversed by BR-DIM treatment. Am J Transl Res. 2013; 6: 102-3.

[144] Wang Z, Chen Z, Gao Y, Li N, Li B, Tan F, et al. DNA hypermethylation of microRNA-34b/c has prognostic value for stage non-small cell lung cancer. Cancer Biol Ther. 2011; 11: 490-6.

[145] Wong KY, Yim RL, So CC, Jin DY, Liang R, Chim CS. Epigenetic inactivation of the MIR34B/C in multiple myeloma. Blood. 2011; 118: 5901-4.

[146] Toyota M, Suzuki H, Sasaki Y, Maruyama R, Imai K, Shinomura $\mathrm{Y}$, et al. Epigenetic silencing of microRNA-34b/c and B-cell translocation gene 4 is associated with $\mathrm{CpG}$ island methylation in colorectal cancer. Cancer Res. 2008; 68: 4123-32.

[147] Siemens H, Neumann J, Jackstadt R, Mansmann U, Horst D, Kirchner T, et al. Detection of miR-34a promoter methylation in combination with elevated expression of c-Met and beta-catenin predicts distant metastasis of colon cancer. Clin Cancer Res. 2013; 19: 710-20. 